\title{
0 paradoxo de Goethe
}

\section{João Carlos Salles Pires da Silva*}

1. Os manuscritos $172,173,176$ do espólio de Wittgenstein, redigidos em 1950 e editados (de modo parcial e até com algum dano) como Anotações sobre as Cores, também podem ser iluminados por uma importante relação entre os parágrafos 53 e 73 do manuscrito 176, qual seja, a relação entre não haver uma fenomenologia (apesar dos muitos e legítimos problemas fenomenológicos) ${ }^{(1)} \mathrm{e}$ não ter Goethe escrito para pintores. ${ }^{(2)}$ Notar esse aspecto das anotações de Wittgenstein é o objetivo desta exposição.

2. Goethe representa bem a tradição que considera o pintor a autoridade mais natural quando se trata de discernir relações entre cores. Essa afirmação, aliás, por força de repetida, tornou-se um lugar-comum. Goethe, afinal, lastimava o artifício newtoniano das experiências circunscritas ao laboratório e, lembra um comentador, "acusava de pobre uma ciência que não vê na cor, por exemplo, senão intensidade maior ou menor de vibrações matematicamente mensuráveis - e Goethe pretendia uma ciência do qualitativo, divorciada da instrumentalização matemática. ${ }^{(3)}$ Sua perspectiva, mais do que científica, é a do artista, a do pintor."(4) Com efeito, Goethe chega a afirmar que sua Doutrina das Cores deixaria gratos sobretudo os pintores, pois com ela colocara-se ao lado da pin-

* Professor do Departamento de Filosofia da UFBA. 
tura, tendo partido, segundo seu juízo, da coloração estética das superfícies $^{(5)}$, a fim de remediar a desastrosa situação em que se encontravam os artistas da cor, então amparados apenas no acaso, em um gosto particular, no costume, no preconceito. ${ }^{(6)} \mathrm{O}$ artista, uma autoridade condenada a reinventar seu ofício, confiando em seu olhar privilegiado. Com sua Doutrina das Cores, porém, a instrução poderia apoiar-se, doravante, não no capricho momentâneo de uma escola, em um gosto subordinado ao costume, que o talento idiossincrático do artista talvez corrigisse, senão no caráter mesmo da cor.

3. O que significa porém esse olhar privilegiado a que pretende servir a Doutrina das Cores, ao tempo em que dele se socorre? Desde priscas eras, afirma, o pintor tem tido a prerrogativa de lidar com a cor.(7) Portanto, de Alberti a Runge, de Delacroix a Kandinski, falar como pintor equivaleria a ocupar o lugar diferenciado da maestria da visão, ditando ademais este olho sensível e treinado $^{(8)}$, junto às regras práticas advindas da experiência da mistura, os princípios mais abstratos da harmonia. Aproximandose, em relação às cores, do ideal próprio de Goethe de um pensar objetivo $^{(9)}$, o olhar do pintor pensaria a cor, sendo o mais propício a colher no visível o caráter da luz. Desse modo, apenas, a experiência da pintura teria produzido uma história da cor autônoma e rica, capaz de contrapor-se naturalmente à "perversão newtoniana" de considerar o branco um composto - para Helmholtz, por sinal, dever-se-ia a uma filiação de artista compelido a procurar beleza e verdade na percepção imediata o excessivo da reação do aquarelista Goethe à hipótese de Newton, o "hetmã cossaco" (10)

4. Segundo Goethe, as relações entre as cores são um sinal a mais, eloqüente embora, do amplo movimento oscilatório da natureza. A natureza sempre fala. Fechamos os olhos e, ainda assim, a um outro sentido, mostra-se ela toda, em "sua existência, sua força, 

realmente é teoria nenhuma"(19), isto é, análises conceituais fixam a essência da cor e não há um experimento crucial que as possa negar e nada todavia pode decidir a seu favor. A Wittgenstein, porém, não basta conceder à Doutrina das Cores a condição de fragmento da lógica dos conceitos de cor, indicando que Goethe, ao elevar-se com o fenômeno primordial à máxima elevação do empírico, confundiu as fronteiras entre a lógica e a empiria; cabe ainda expor a unilateralidade dessa análise fenomenológica.

6. Um dos recursos característicos de sua técnica é a produção de exemplos, inclusive fictícios, que sirvam para testar, em situaçõeslimite, a identidade de nossos conceitos ${ }^{(20)}$; desse modo, Wittgenstein não deixa de imaginar várias situações em que leis da Doutrina das Cores parecem perder sua vigência. Situações extremas desafiam então o emprego de termos cromáticos os mais inocentes, como o simples e puro 'branco' Toda uma legião estrangeira, bem o sabemos, povoa exemplarmente seus textos, retirando nossos conceitos mais familiares de suas circunstâncias normais de uso. E isso não porque seu interesse, como o seria o de uma psicologia, seja identificar um desvio ou defeito e explicar, e. g., a cegueira para cores, mas sim por ser este um modo de abrir caminho para uma investigação filosófica sobre a visão "normal" ou sobre a normalidade da visão, uma vez que a variação de exemplos explicita razões que costumamos aceitar como critérios de identidade e servem para justificar nossas aplicações habituais. ${ }^{(21)}$ Analisemos, então, com Wittgenstein, um enunciado canônico da Doutrina das Cores: "O perfeito turvo é o branco, o primeiro e mais neutro (gleichgültig) e mais claro preenchimento não-transparente do espaço" (22) Mas consideremos desse enunciado apenas uma parte e enquanto uma regra de representação de nossa experiência visual: O branco é a cor mais clara ${ }^{(23)}$ - norma de representação, que Goethe não distingue de uma evidência científica, conquanto a diga eterna, necessária. 
7. Se em um quadro um pedaço de papel recebe sua clareza de um céu azul, pelo menos em um sentido o céu azul é mais claro que o papel branco. Na paleta, entretanto, separadas ou misturadas as cores antes de sua aplicação na tela, o branco é a cor mais clara; logo, neste outro sentido, visadas suas relações internas, seu notório parentesco com o preto, o azul é a cor mais escura. ${ }^{(24)}$ Eis, nesse ponto, o sentido da algo misteriosa e amiúde mal interpretada afirmação de Wittgenstein de que as observações de Goethe seriam inúteis ao pintor, não dariam conta do uso das cores em um quadro, do ver dessas cores, e apenas seriam um pouco úteis ao decorador. ${ }^{(25)} \mathrm{O}$ problema estaria em que, ao falar do caráter de uma cor, ao descrever o que seria seu "fenômeno primordial"(26), Goethe só pode estar pensando em um modo único de seu emprego. No caso, apesar de, por exemplo, ter traduzido e comentado, em 1798, os Ensaios sobre a Pintura de Diderot, nos quais são fortes e claras tanto a distinção entre a paleta comportada do protocolista e a paleta do colorista (uma imagem do caos) quanto a distinção entre a própria cor na paleta e seu efeito no quadro, sendo diversos os critérios da identidade da $\operatorname{cor}^{(27)}$; apesar do semnúmero de experimentos que realiza, da variedade de exemplos que contempla e acumula; apesar, enfim, de seu rico arsenal de informações conflitantes sobre a história "natural" da cor, ao fazer fenomenologia, Goethe obriga-se a pensar as cores reduzindoas conceitualmente à limitada aplicação na paleta (ou a uma assemelhada), quando o branco é cor de matéria e as cores outras, sombreamentos, matérias de cor que, em síntese subtrativa, só podem dirigir-se ao negro. Ou ainda, no trabalho do aquarelista, com o branco fora da paleta, é o branco do papel que a cor vem sujar ou escurecer.

8. A semelhança pervade os casos, como a clamar em favor do fenômeno primordial da cor e a confirmar o princípio da cor como um encontro da luz com um meio túrbido, corpóreo, sombreado. 

ções para pintores, aprende as lições dos pintores, traduzindo o problema da percepção de uma cor em ações específicas e o olhar em procedimentos nunca exteriores à linguagem. $\mathrm{O}$ 'dar instruções ao pintor' desloca a discussão sobre as cores para o interior da gramática de um jogo mais amplo, para a gramática do 'ver' e também para um conjunto nada unilateral de técnicas, um conjunto heterogêneo como a linguagem ela própria; com isso, Wittgenstein desloca a descrição da experiência perceptiva do universo aporético de uma interioridade inefável para o campo de jogos precisos e públicos, quebrando inclusive a ilusão antiga de um acesso imediato ao mundo dos sentidos. Wittgenstein não abandona, porém, o terreno de uma análise conceitual; antes reconhece que jogos de linguagem diversos, empregos mais ricos de um conceito, constróem ou são possíveis por outras relações internas - com o que se preservam legítimos problemas fenomenológicos, embora insusceptíveis da "análise fenomenológica (como Goethe, por exemplo, a queria)" (36)

11. "Quem concorda com Goethe, afirma Wittgenstein, acha que ele teria reconhecido corretamente a natureza da cor. E natureza não é aqui o que decorre de experimentos, mas sim o que reside no conceito de cor." (37) Ou seja, a natureza é a síntese das relações internas, a determinação essencial de um conceito, tal como pode ser determinada, com relativo fechamento, em certos empregos. Se Goethe, por exemplo, acertou com a natureza das cores, a natureza é em sua Doutrina das Cores puro conceito, deriva de assunções de evidência não-física, como a de que da escuridão (das cores que são como sombras) não pode provir a claridade, o branco. ${ }^{(38)}$ O branco não é uma cor intermediária entre outras, sendo repulsivo pensá-lo como resultante de mistura; assim, não é analisável em, por exemplo, um azul esverdeado, avermelhado e amarelado, ou coisa semelhante. ${ }^{(39)}$ Diante de uma tal convicção, a teoria de Newton só poderia mesmo parecer uma "perversão infer- 
nal da verdade" Mas o branco, o branco com que descrevemos nossa experiência perceptiva e não o branco puro de Lichtenberg (aquele em que o emprego usual foi refinado unilateralmente e não ocorre em lugar algum, salvo em laboratório, no exagero sem circunstância de uma conceitografia cromática), nosso branco, em sentidos diversos, é e não é a cor mais clara - como uma cor seria suja como cor de uma parede mas não seria suja em uma pintura. ${ }^{(40)}$

12. Não por desconhecimento de tradição bem estabelecida e consentânea com a intenção do poeta, Wittgenstein enunciou essa sua heresia: Goethe não escreveu para pintores. Essa seria sua paradoxal situação, atestado sofisticado da falência de seu projeto fenomenológico: deixar de escrever para a autoridade a que deveria preferencialmente dirigir-se. Mais ainda: Goethe encontra-se nessa situação paradoxal de fazer má fenomenologia, apenas por pretender fazê-la. Sumamente paradoxal é o projeto da própria fenomenologia e notável sua incapacidade diante de lídimos problemas fenomenológicos, caso pretenda dirigir-se a essências fixando a identidade da cor, porquanto deixa então de escrever para suas autoridades preferenciais e superiores, servindo quando muito a decoradores, ou seja, a jogos conceituais limitados - com o que Wittgenstein alude talvez à descrição de Goethe dos efeitos da cor em ambientes quase monocromáticos, com o uso de papéis de parede coloridos, etc. ${ }^{(41)}$, embora duvide de sua utilidade mesmo nesse emprego reduzido, pois, conforme acrescenta, "a cor de um de olho injetado de sangue poderia produzir um magnífico efeito como cor de um papel de parede" (42) Uma tal fenomenologia seria, pois, incapaz de abandonar-se ao aprendizado da cor, no qual os pintores, com suas convenções e seus preconceitos, muito têm a ensinar. A fenomenologia de Goethe não daria conta da heterogeneidade do jogo da ocorrência cromática e dos jogos outros em nada exteriores ao emprego correto das palavras com que descrevemos nosso campo visual. Assim, fechar-se-ia para a ex- 
periência da pintura o que se dirigia ao pintor, deixando na sombra a autonomia da ocorrência cromática a que pretendia dar a expressão da lei. ${ }^{(43)}$ Se Goethe pretende ter sido bem sucedido ao encontrar o fenômeno primordial da cor, a matriz da série toda de fenômenos cromáticos, no caso, a cor como uma espécie de confronto da luz com meios túrbidos, o sucesso da análise fenomenológica de Goethe coincide então com seu fracasso, pois não há com as cores fenômeno primordial algum de história natural, como ao contrário talvez haja com plantas e animais. ${ }^{(44)}$

13. A possibilidade de fazer, ao mesmo tempo, ciência e filosofia, de escrever assim para o filósofo como para o físico, sustentar-seia, na Doutrina das Cores, no privilégio concedido ao olhar, ao mais refinado dos instrumentos, lugar objetivo e subjetivo da cor, cifra da natureza enquanto visível. Desse modo, as Anotações sobre as Cores não apenas sugerem um paradoxo nesse exercício morfológico de Goethe, como sobretudo são uma extensa crítica a esse seu fundamento. Sobre cores, insiste Wittgenstein, não aprendemos por olhar; por exemplo, não pode ser visto se o verde é uma cor primária ou um misto fenomenal. Se, em certos momentos, devemos constatar que estamos diante de um "fenômeno primordial", o fenômeno que encontramos como primeiro é apenas: este jogo de linguagem é jogado ${ }^{(45)}$, não havendo ademais com cores um jogo único, conceitográfico e excludente. Wittgenstein dirigese, desse modo, a problemas fenomenológicos abandonando o privilégio do olhar que favoreceria a autoridade dos pintores, mas absorvendo ao contrário a experiência privilegiada da pintura tal como ela sistematiza mais um jogo de linguagem por que falamos de cores. ${ }^{(46)}$ A lógica dos conceitos de cores não se subordina assim a um jogo único, homogêneo, dependente do caráter das cores, sobretudo porque as cores não são coisas com caráter determinado, sendo antes colhidas em jogos heterogêneos, como o exemplificamos com o problema da clareza do branco. 
(15) Cf. Goethe, J. W, Zur Farbenlehre, § 60. Goethe não chega contudo ao enunciado da complementaridade, quer em seu sentido físico, quer no sentido gramatical. Seu conceito de cores opostas ou evocadas (entgegengesetzte ou geforderte Farben) coincide com o de cores complementares tão-somente em sua extensão e nunca em sua compreensão, não sendo justificável que nos sirvamos da expressão 'cor complementar' para traduzir suas ocorrências. Não são complementares fisicamente, uma vez que não tendem em síntese aditiva ao branco nem em subtrativa ao preto. Para Goethe, convém lembrar, o branco não é um composto. Considerá-lo assim: eis a exata perversão newtoniana: "Denk an den Abscheu Goethes vor der Idee, Weiß sei zusammengesetzt. Was heißt hier "zusammengesetzt"? und was heißt hier "einfach"?" (Wittgenstein, Ludwig, The Wittgenstein Papers, vol. 35, MS 133, p. 32.) Tampouco seriam complementares no sentido gramatical de não descreverem juntas qualquer fragmento da experiência sensível, porquanto Goethe chega a admitir sua ocorrência simultânea em pontos de contato de manchas opostas, antecipando em mais de um século uma das tentativas de refutação da teoria dos canais oponentes (Cf. Goethe, J. W, Zur Farbenlehre, § 43).

(16) Cf. Goethe, J. W, Zur Farbenlehre, § 708. À altura da redação de Zur Farbenlehre, a totalidade já equivalia à complementaridade tanto para um Rumford, para quem duas sombras coloridas só estariam em perfeita harmonia quando a mescla de suas colorações causasse a sensação do branco, como sobretudo para um Hassenfratz, que descreveu relações complementares com extraordinária precisão. Note-se que Goethe já tinha ciência nesse momento desses trabalhos. Cf. Roque, Georges, "Les Couleurs Complémentaires: un nouveau paradigme" A polaridade seria uma força cega da natureza que só a intensificação, outro princípio motor, poderia sublimar. Cf. Gusdorf, Georges, Le Savoir Romantique de la Nature, p. 84ss. Desse modo, a totalidade que o olho exige não é mais que lei física, não teria um critério exterior ao simples equilíbrio de forças, ou seja, a totalidade, o contraste harmônico, não dispõe de critério exterior à oposição física de que almeja diferenciar-se - um critério com que as cores acidentais passarão a alimentar novo paradigma na história da cor.

(17) A mera harmonia como efeito da justaposição de cores opostas é tão gramatical quanto o repouso provocado pelo equilíbrio de forças, ou seja, é gramática alguma. O círculo crom ́́tico, determinação do olho, é assim por completo divorciado da linguagem e redutível a fatos empíricos. Goethe não compreendeu como Runge o problema; por isso, é Runge 
tem qualquer caráter, salvo em específicos contextos. Vale notar também que, ao contrapor os experimentos e vocabulário da Gestalt ao emprego limitado e indevidamente generalizado de um Goethe, Wittgenstein também reciprocamente está contrapondo o que funciona (e bem) auf der Pallete à generalização de um modelo de descrição da experiência visual que, também ele, pretendeu cifrar (de um golpe e segundo certos exemplos tornados canônicos) toda a experiência do ver.

(26) O fenômeno primordial situa o cientista como que na elevação máxima do empírico (Cf. Goethe, J. W., Zur Farbenlehre, § 720), nada podendo ser-lhe superior no mundo dos fenômenos e cada caso sendo dele passível de derivação. No caso da cor, tal fenômeno primordial seria: "Wir sehen auf der einen Seite das Licht, das Helle, auf der andern die Finsternis, das Dunkle; wir bringen die Trübe zwischen beide, und aus diesen Gegensätzen, mit Hülfe gedachter Vermittlung, entwickeln sich, gleichfalls in einem Gegensatz, die Farben, deuten aber alsbald, durch einen Wechselbezug, unmittelbar auf ein Gemeinsames wieder zurück" (Cf. Goethe, J. W., Zur Farbenlehre, § 175).

(27) "Eis em uma tela uma mulher vestida de cetim branco; cobri o resto do quadro e olhai somente a vestimenta: esse cetim vos parecerá talvez sujo, fosco, pouco verdadeiro; mas restitui essa mulher ao lugar no qual está rodeada de objetos e, imediatamente, o cetim e sua cor retomarão seu efeito." (Diderot, Denis, Ensaios sobre a Pintura, p. 50.)

(28) Cf. Goethe, J. W. Zur Farbenlehre, §§ 573-575. Misturas fisiológicas, físicas ou químicas confirmam o fenômeno primordial, traduzem a mesma idéia, mostram todas o parentesco essencial da cor com o cinza, com esse representante da penumbra (Cf. Goethe, J. W., Zur Farbenlehre, § 259), sendo a perversão newtoniana uma transformação do simples em um composto e do composto em simples (Cf. Goethe, J. W., Zur Farbenlehre, § 176). Goethe trata, portanto, da mesma forma, a gama empírica e a gama estética, não distingue síntese aditiva de subtrativa, mistura aparente de real: todas escurecem, não produzem o branco ou não podem ser mais claras que o branco (Cf. Goethe, J. W., Zur Farbenlehre, $\S \S 558-559$ ), pois mesmo a cor mais clara contém escuridão (Cf. Goethe, J. W., Zur Farbenlehre, § 699), sobretudo o azul, que sempre implica algo escuro, por sua afinidade com o preto (Cf. Goethe, J. W., Zur Farbenlehre, § 538 e $§ 778$ ).

(29) O cinza assim pode ser visto corr o branco em certos contextos, mas, proíbe-o a lógica dos conceitos de cor, não será visto de modo algum como 
branco, caso sua variação de tons seja indicativa de profundidade ou transparência.

(30) Wittgenstein, Ludwig, Bemerkungen über die Farben, III, § 57. Enquanto Goethe, ao contrário, fixa o caráter da cor, até no limite de as tornar únicas em um quarto, de modo a derivar seus efeitos "morais" Eis como ensinaria alguma coisa ao decorador.

(31) Cf. Goethe, J. W., Zur Farbenlehre, §§ 556 a 559.

(32) Cf. Wittgenstein, Ludwig, Bemerkungen über die Philosophie der Psychologie, I, § 47. Vale também ter em conta, além de sua experiência de aquarelista, as considerações de Goethe sobre a superioridade da pintura que parte de um fundo branco, que é feita sobre uma base branca. Cf. Goethe, J. W., Zur Farbenlehre, \$§ 902 a 910.

(33) Vale a pena apresentá-lo com todas as suas variantes: "[/] As dificuldades que / encontramos ao refletir sobre a essência das cores // se sente ao refletir sobre a essência das cores // (às quais Goethe quis fazer frente com sua doutrina das cores), / encerram-se já em não termos / apenas um // um // conceito da igualdade cromática, mas sim vários deles, uns aos outros aparentados. // residem já na multiplicidade de aspectos de nosso conceito de igualdade cromática. // // encerram-se já na / multiplicidade // multiformidade // dos conceitos aparentados da igualdade cromática. / /// encerram-se já na / multiplicidade // multiformidade // / do // de nosso // conceito de igualdade cromática. //" (Wittgenstein, Ludwig, Bemerkungen über die Farben, III, § 251.)

(34) Cf. Wittgenstein, Ludwig, Bemerkungen über die Farben, III, § 255.

(35) Cf. Wittgenstein, Ludwig, Bemerkungen über die Farben, II, §§ 1-3 \{11$13\}$.

(36) Wittgenstein, Ludwig, Bemerkungen über die Farben, II, § $6\{16\}$.

(37) Wittgenstein, Ludwig, Bemerkungen über die Farben, I, § 71. Cf. também III, $\S 125$ e 126.

(38) Em Letzte Schriften über die Philosophie der Psychologie, § 218, Wittgenstein, após apresentar-nos a descrição goetheana das cores como sombras, comenta: "'”Várias sombras dão juntas a luz." - Esta proposição poderia quase aparecer como uma perversão infernal da verdade."

(39) Cf. Wittgenstein, Ludwig, Bemerkungen über die Farben, I, §§ 70-72; III, $\S 125-126$. Uma proposição curiosa da Farbenlehre, que bem pode simular estatuto científico, é a representação de como veria o mundo um acianobléptico (cego para o azul). (Cf. a primeira lâmina da Farbenlehre, 
in Goethe, J. W., Die Tafeln zur Farbenlehre und deren Erklärung, p. 9) Não estaríamos porém em situação aporética se pensássemos tal proposição como uma hipótese a ser submetida ao teste do mundo? Afinal, como descrever do interior outro universo cromático? A psicologia descreve o desvio, pode inclusive medi-lo, submeter a testes a acuidade visual ou o daltonismo. Entretanto, Goethe vai além. Exibe outra normalidade. Quem pode todavia decidir se vê ou não o mundo como ele nos propõe é o próprio cego para cores; mas, como comparar um "falso" quadro do mundo com um mundo "real" tal como os cegos para cores o vêem?

(40) Cf. Wittgenstein, Ludwig, Bemerkungen über die Farben, III, § 89. A identidade do conceito de cor depende de técnicas de comparação, instala-se em certos jogos, sendo difícil aplicar o conceito de identidade de cor ao que vemos, não sendo claro por si o que deve ser aceito para comparação de tons de cores. O ver reporta-se a comportamentos específicos, envolvendo contudo um aspecto conceitual que não pode ser reduzido a relações causais nem assim à alçada da psicologia, preservando-se portanto como lídimo problema fenomenológico.

(41) Cf. Goethe, J. W., Zur Farbenlehre, §§ 765-802.

(42) Wittgenstein, Ludwig, Bemerkungen über die Farben, I, § 73.

(43) Com isso, deixa de escrever para pintores por cometer o grande engano de julgá-los autoridades preferenciais por conta de um olho privilegiado, quando os pintores nos instruem melhor se compreendemos que sobre cores não aprendemos por olhar.

(44) Wittgenstein, Ludwig, Bemerkungen über die Philosophie der Psychologie, I, § 950.

(45) Wittgenstein, Ludwig, Philosophische Untersuchungen, § 654.

(46) O círculo cromático deixa de cifrar fatos empíricos sobre o olho, como se fora sua determinação interna ou expressão de leis da natureza. "It [o círculo cromático, ou um modelo como o octaedro] is more properly seen as a graphic device for expressing certain of the logical relationships which hold between the colour concepts implicit in the languages human beings use in the language games constitutive of their day to day lives." (Stock, Guy, "Review: Remarks on Colour" pp. 449-450.) Neste sentido, a cor não tem uma estrutura, não tem um caráter, ou melhor, as cores têm estrutura, não necessariamente única, se os jogos de linguagem com cores tecem relações internas.

(47) Wittgenstein, Ludwig, Bemerkungen über die Farben, IV, §§ 5-7. 


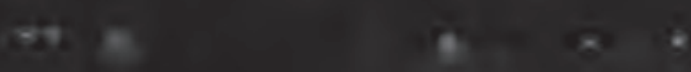


